\title{
Currents and Fisheries of the North Sea
}

$\mathrm{D}^{2}$ URING recent years the study of marine biology has been prosecuted with great vigour by most of the maritime countries of the world, with the result that remarkable progress has been made in the elucidation of the habits and life-histories of marine organisms. Much knowledge has now been accumulated concerning those great fluctuations in the stocks of economic fishes which from time immemorial have disconcerted the fishing industries of this and every other country in which fishing activities are carried on. Such outstanding progress has in fact been made in this direction that, for some fishes at least, notably the haddock and the herring, it is now possible to make reasonably accurate forecasts concerning the magnitude of the fish stocks-and therefore of the prospects of the respective fisheries-a year or even two years in advance.

These forecasts have in the past been based largely, if not entirely, upon purely biological and biometrical studies of the fish stocks themselves and of the changes taking place within them.

But although these population fluctuations can now be followed in great detail, the question of what are the causes underlying them still remains unanswered. With the progress of marine research, however, it becomes increasingly evident that the further elucidation of this problem must be sought in a more intensive study of the environment that is to say, of the physical and chemical properties of the sea itself.

Now one of the most outstanding and most important characteristics of the sea is its constant and more or less complex motion. It is particularly noteworthy, therefore, that the entire afternoon session of Tuesday, September 11, was devoted by Section D (Zoology) of the British Association at Aberdeen, to a very full discussion of "The Currents of the Sea and their Biological Importance" in which the following took part: Dr. J. B. Tait, Fishery Board Laboratory, Aberdeen; Dr. J. N. Carruthers, Fisheries Laboratory, Lowestoft; Prof. A. C. Hardy, University College, Hull ; and Dr. E. R. Gunther, of the scientific staff of the "Discovery" Committee. In the course of this discussion, it was pointed out that, from the biological point of view of the environmental relationship of fishes, the importance of the sea's constant movement lies in the fact that the physical conditions of almost every region are thereby subject to continuous change. Moreover, fishes are dependent upon certain movements in the sea for the conveyance of much of their food to the regions they inhabit. These same movements further control the passive migrations of the eggs of most fishes and of their young stages before their swimming powers have developed. The movements of the sea have thus a double effect from the biological point of view, first because of their purely mechanical effects and secondly as governing the physical and chemical conditions of any given region. In both these respects, it is the horizontal movements or currents, especially those of the upper water layers, which are generally of most importance; although Dr. Gunther pointed out that in some regions at least-notably on the west coast of South America-vertical currents are of fundamental biological importance.

The measurement of horizontal currents in the sea presents numerous practical difficulties. In the northern North Sea these difficulties have been mainly overcome by the use of drift-bottles of suitable design. Recent analyses of elaborate drift-bottle experiments confirm the presence of extensive drift-currents in the northern North Sea. These currents can, and do, often possess chemical and physical properties very different from those of the adjacent waters on either side. Such great variations in the properties of the water as are occasionally noted within a short interval of time at the same hydrographical station may therefore well be due to alteration in the direction of flow of a stream current and not, as is usually implied, to such radical hydrographical changes as betoken large and rapid hydrodynamical variations; for it can be taken as a general rule that modifications in the physical phenomena of the sea in which time is an essential factor do not take place with marked suddenness. The drift-bottle and hydrographical records further show that the main stream current affecting the northern North Sea is that which brings in Atlantic water around the north of Shetland through the Faroë-Shetland Channel.

In the southern North Sea, the hydrographical conditions are governed largely by the flow of water through the Straits of Dover. By means of a current meter attached to the Varne Lightship, data concerning the strength and direction of this current have been collected continuously over the last eight years. The varying water movements observed, when balanced out over a term of years, have effected the same overall transport of water as would have been accomplished by a very slow river flowing at the rate of about $\mathbf{3} \cdot \mathbf{2}$ miles a day from the English Channel into the North Sea. In certain circumstances the current flows the other way. Following winds quicken it and head winds impede it. A play of such wind conditions over the North Sea at large, as would be expected to pool up the Southern Bight (and north-westerly wind conditions are well known to do this), can most effectively hold up and reverse the current.

The results of the last three years are of especial interest, for, instead of the residual current heading boldly into the North Sea (as it most frequently had done in the previous three years) it has displayed less and less easting with the passage of time. During 1933, the current headed about half a point west of north.

Such long-enduring modifications of the current are held to be analogous in a way to the short-lived modifications produced by wind influence. The inferred cause, in their case, however, is an oceanic pulse-an accession of strength on the part of the parent supply stream which flows in from the ocean round the north of Scotland. This causes an extra strong southward urge of waters through the North Sea-with the results observed in 1933 particularly.

The Dover Straits current attains its strongest and weakest rates of flow a half year later than does the current entering the North Sea round the north of Scotland, but a quarter year later than the current in the Cromer Knoll region.

These facts are interpreted to indicate that the Dover Straits current waxes and wanes through the year in a sort of buffer relationship with the current from the North-that there exists a sort of seesaw conflict between the two. The vagaries of the Dover Straits currents are, on the strength of the findings mentioned, held to serve as pointers to 
major modifications of the currents in the northern and middle reaches of the North Sea half a year earlier.

The results obtained from the current measurements in question have been applied to various problems of fishery interest. Amongst those of immediate local concern, that is, germane to the southern North Sea, there are the questions of good and bad survival years for the plaice and for the herring of the great East Anglian autumn fishery. The latter originate from vast annual spawnings in the eastern end of the Channel. It seems that good fortune has attended the broods of both fish when, during the egg and/or fry stages, the current issuing from Dover Straits has been most average in point both of strength and direction. This accords with the supposition that good augury for a plaice brood exists when the products of the spawning are transported to the Continental coastal shallows-the so-called young plaice nursery grounds.

Other problems calling for the application of the Varne lightvessel current data in their local rôle are concerned with the intermingling of two types of herring through the Straits, and with the outcome of the Belgian spent herring fishery. This latter is carried out upon fish supposedly enfeebled by the operation of spawning in the eastern channel.

Applied at a distance as it were, on the strength of the facts set out above, the Dover Straits current data enable something to be said about good and poor haddock years. The haddock fluctuates very closely (though oppositely) with the herring, and seems, when in the egg and fry stage, to have experienced the best survival conditions when we should judge the waters to have been most strongly urged towards the south.

The year-class fluctuations of the cod have been studied side by side with meteorological data, and it appears that the best augury for a brood obtains in those spawning seasons during which winds from the half-compass centred on north-east have been at a maximum-a finding which accords well with what is inferred in the case of the haddock from the Varne current data.
G. A. S.

\section{Translocation in the Cotton Plant}

$\mathrm{T}$ $\mathrm{HE}$ cotton plant continues to be a fruitful source of information regarding the movement of materials in plants. Phillis and Mason", in a paper which deals more particularly with the transport of carbohydrate out of the leaves into the vascular tissue, have re-examined the evidence which led Mason and Maskell ${ }^{2}$ to the conclusion that carbohydrate was exported from the mesophyll as reducing sugar and condensed to sucrose in the phloem of the transporting tissue, and that carbohydrate is translocated in the form of sucrose along concentration gradients in the phloem.

The results of Phillis and Mason, derived from an elaborate series of ringing experiments and determinations of diurnal fluctuations in the concentration of sugars in the lamina and petiole, indicate that sucrose, and not reducing sugar, is the form in which carbohydrate is moved from the mesophyll to the veins as well as longitudinally down the petiolar phloem. They find further that the concentration of sucrose is greater in the vein and petiole than in the mesophyll, suggesting that sucrose is accumulated against a concentration gradient. By subdividing the petiole into wood and inner and outer bark, they concluded that this accumulation occurred in the phloem region, and an examination of the distribution of sieve-tubes and companion cells indicated the localisation of the process in the large companion cells and undivided phloem mother cells of the fine veins. These 'transition cells' thus remove sucrose from the leaf parenchyma and liberate it to the sieve tubes of the veins, whence it is transported by a diffusion process down concentration gradients. The problem of translocation is thus further complicated by the additional problem of accumulation against a concentration gradient, a mechanism which is far from being completely understood even in the case of much simpler substances than sucrose.

No. 5 of the Memoirs of the Cotton Research Station, Trinidad, 1934, contains two further papers by Mason and Maskell. The first ${ }^{3}$ deals with the transport of phosphorus, potassium, calcium and nitrogen. The results indicate that these elements move upward in the xylem, and with the exception of calcium, are re-exported from the leaf and move downwards in the phloem. Estimations of the ratios of nitrogen, phosphorus and potassium to carbohydrate moving downwards from the leaves indicate that these elements are probably in excess of the amounts required for growth of the lower tissues. It is suggested that mineral elements ascend the stem from the roots with the transpiration current, passing with the bulk of the water to the leaves, where accumulation occurs together with the synthesis of organic compounds. Downward movement of these mineral substances is accompanied by leakage laterally, not only to the growing and storage tissues but also into the trachex, in which they may be moved upward again by the transpiration stream. Calcium was not appreciably re-exported from the leaf and seems incapable of moving in the phloem, facts which the authors suggest may be correlated with the combination of this element with cell contents, or the relative impermeability of the cell membranes.

The other paper* consists of the examination of changes in the concentrations and vertical gradients of mineral elements and carbohydrates in relation to ontogeny, the object being to derive evidence to show whether transport occurs by a diffusion mechanism determined by individual concentration gradients for each substance moved or by "a mass flow of sap containing all the mobile materials" from a region of higher to one of lower turgor pressure. Negative gradients from the foliage region downwards were found for nitrogen, phosphorus, potassium and calcium, but it is suggested that the "dynamic gradient of mobile material was being masked by a static gradient of storage or immobile material".

In the case of nitrogen, a positive gradient of residual nitrogen is shown to be almost completely masked by the storage of asparagine, which results in a steep negative gradient of crystalloid nitrogen. Except in the case of potassium, the evidence for 